\title{
Algas DE FUENTES TERMALES DEL NW DE España: Baños de Molgas Y Caldas de Partovia
}

\author{
Angela NOGUEROL SEOANE
}

RESUMEN: Se estudia la composición algal de las termas «Baños de Molgas» $\mathrm{y}$ «Caldas de Partovia», incluyendo algunos datos físicos y químicos de las aguas. De los 15 táxones identificados, el mayor recubrimiento lo proporcionan: Mastigocladus laminosus, en Baños de Molgas; Phormidium corium, en Caldas de Partovia. Symploca thermalis y Phormidium treleasei, en ambas.

Palabras clave: Algas, fuentes termales, NW de España.

ABSTRACT: The composition of the algae and some physical and chemical data of the water found in the hot springs known as «Baños de Molgas» and "Caldas de Partovia» has been studied. From the fifteen taxa identified, the major covering is formed by: Mastigocladus laminosus in the Baños de Molgas; Phormidium corium in the Caldas de Partovia. Symploca thermalis and Phormidium treleasei in both of them.

Key words:Algae, hot springs, NW of Spain.

\section{INTRODUCCIÓN}

Baños de Molgas está situada en la depresión de Maceda (Ourense) al margen izquierdo del río Arnoya. Geográficamente se halla a $42^{\circ} 14^{\prime} 28^{\prime \prime}$ de latitud y $7^{\circ} 40^{\prime}$ $15^{\prime \prime}$ de longitud, siendo su altitud aproximada de $500 \mathrm{~m}$.

El biotopo estudiado fue una fuente artificial de cantería cuya cubeta, alimentada por el agua de un caño, mide alrededor de $0,78 \mathrm{~m}$ de largo por 0,63 de ancho y 0,35 de profundidad. El agua excedente drena por un canal de salida.

Caldas de Partovia se encuentra en el extremo noroccidental de la provincia de Ourense, a $2 \mathrm{~km}$ de la villa de Carballiño. Sus coordenadas geográficas corresponden a $42^{\circ} 24^{\prime} 30^{\prime \prime}$ de latitud y $4^{\circ} 22^{\prime} 45^{\prime \prime}$ de longitud. Su altitud es, aproximadamente, 350 m. 
Las muestras se recogieron en lo que actualmente funciona como lavadero público, adosado al edificio balneario por su parte externa. La cubeta, de cerámica bastarda cubierta de pasta, mide 2,35 m de largo por 1,60 de ancho y 0,35 de profundidad. El agua que recibe proviene del manantial caliente que aflora en el interior del edificio y que pasa a la cubeta a través de una piedra plana protegida por una terraja.

El clima, en ambos enclaves, se caracteriza por sus temperaturas suaves (media anual de $11-12^{\circ} \mathrm{C}$ ) y no muy contrastadas (oscilación de 5- $6^{\circ} \mathrm{C}$ en el mes más frío y $18-19^{\circ} \mathrm{C}$ en el más cálido). La precipitación es superior a $1.200 \mathrm{~mm}$ anuales.

\section{MATERIAL Y MÉTODO}

Las muestras se recolectaron por duplicado en distintos puntos de las fuentes en mayo de 1988, fijando una de las partes con formol al $4 \%$. Asimismo se obtuvieron valores de $\mathrm{pH}$, conductividad y temperatura, utilizando para ello instrumental Crison Portable. Los valores de las determinaciones analíticas de las aguas las hemos tomado de San Martín (1989) para Baños de Molgas y, por comunicación oral, las efectuadas para Caldas de Partovia por el Instituto Geológico y Minero de España.

\section{RESULTADOS}

Las características de las aguas se dan en la Tabla 1.

B. Molgas

\begin{tabular}{|c|c|c|}
\hline \multicolumn{3}{|l|}{ Cationes mg/1 } \\
\hline $\mathrm{Na}+$ & 228,64 & 45,20 \\
\hline $\mathrm{K}+$ & 10,77 & 1,10 \\
\hline $\mathrm{Ca}++$ & 21,84 & 0,90 \\
\hline $\mathrm{Mg}++$ & 1,71 & 0,10 \\
\hline \multicolumn{3}{|l|}{ Aniones mg/1 } \\
\hline $\mathrm{CO}_{3} \mathrm{H}^{-}$ & 685,40 & 61,10 \\
\hline $\mathrm{Cl}^{-}$ & 13,68 & 14,20 \\
\hline $\mathrm{SO}_{4}=$ & 1,41 & 5,20 \\
\hline $\mathrm{NO}_{3}$ & 0,00 & 0,90 \\
\hline Residuo seco & & \\
\hline a $110^{\circ} \mathrm{C}(\mathrm{mg} / \mathrm{1})$ & 716,00 & 176,10 \\
\hline $\begin{array}{l}\text { Conductividad } \\
\mu \text { Scm }-1\end{array}$ & 1,05 & 0,00 \\
\hline Temperatura ${ }^{\circ} \mathrm{C}$ & $44-46$ & $30-31$ \\
\hline pH & 6,99 & 9,03 \\
\hline
\end{tabular}

Tabla 1 
Catálogos florísticos: La relación de los táxones se dan por orden alfabético dentro de cada clase.

\section{BAÑOS DE MOLGAS :}

Cyanophyceae

Chroococcus minimus (Keissler) Lemmermann; Lyngbya aerugineo-coerulea (Kützing) Gomont; Mastigocladus laminosus (Kützing) Cohn; Myxosarcina ef burmensis Skuja; Oscillatoria planctonica Woloszynska; Phormidium treleasei Gomont; Symploca thermalis (Kützing) Gomont.

\section{CALDAS DE PARTOVIA}

Cyanophyceae

Dermocarpa sp; Johannesbaptista sp; Lyngbya lutea (C. Agard) Gomont; Lyngbya martesiana Meneghini; Oscillatoria tenuis C. Agardh; Phormidium corium (C. Agardh) Gomont; Phormidium treleasei Gomont; Phormidium valderianum (Delp.) Gomont; Symploca thermalis (Kützing) Gomont

Bacillariophyceae

Navicula cari var. angusta Grunow

\section{DISCUSIÓN}

El bajo número de táxones en estas fuentes, puede ser debido a la escasa amplitud térmica del agua en los distintos puntos de las mismas, io que limita las posibilidades de población a especies con carácter estenotérmico. Estos resultados coinciden con los obtenidos por Guarrera (1961) y Maillard (1981) para cianofíceas, en fuentes termales de Argentina y Normandía, respectivamente.

El hecho de que en Caldas de Partovia la heterogeneidad específica sea superior a la registrada en Baños de Molgas, es consecuencia de que la temperatura del agua es más baja en el primer biotopo, al mismo tiempo que el pH es más elevado (Brock, 1967; Noguerol Seoane, 1984).

La ausencia del alga termófila cosmopolita Mastigocladus laminosus en Caldas de Partovia, se debe a que sólo puede desarrollarse a temperaturas comprendidas entre $45-65^{\circ} \mathrm{C}$ (Muster et al., 1983).

Cabe señalar que al tratarse de fuentes sometidas a limpieza periódica, no siempre es posible encontrar las poblaciones bien desarrolladas.

\section{CONCLUSIONES}

En la fuente termal denominada Baños de Molgas, se han identificado un total de 7 táxones, todos ellos pertenecientes a la Clase Cyanophyceae. De la terma Caldas de 
Partovia 10, de los que 9 son Cyanophyceae y 1 Bacillariophyceae.

El mayor recubrimiento lo proporcionan: Matigocladus laminosus y Phormidium corium en baños de Molgas y Caldas de Partovia, respectivamente; además de Symploca thermalis y Phormidium treleasei en ambas. Estas especies, salvo Phormidium corium, tienen marcado carácter termófilo.

\section{BIBLIOGRAFÍA}

BROCK, T. -1967- Live at high temperatures. Science, 24(158) 3804:1012-1019.

GUARRERA, S.A. -1961- Algas termales de la provincia de Salta (República Argentina). Cyanophyta. Bol. Soc. Argentina de Bot., 9:199-215.

MAILLARD, R. -1981- Florule algale d'une source chaude en Normandie (France). Cryptogamie Algol., 2:141-145.

MUSTER, P., A. BINDER, K. SCHNEIDER \& R. BACHOFEN -1983-Influence of temperature and $\mathrm{pH}$ on the growth of the thermophilic cyanobacterium Mastigocladus laminosus in continuous culture. Plant and Cell Physiol., 24(2):273-280.

NOGUEROL SEOANE, A. -1984-Cianofíceas termófilas de «As Burgas» (Ourense). Anales Biol. Univ. Murcia. 2 (Secc. esp. 2):127-133.

SAN MARTÍN BACAICOA, I. -1989- Balneario de Molgas. Bol. Soc. Esp. Hidrol. Med., 4(1):37-41.

(Aceptado para su publicación en Junio de 1.990 )

Dirección del autor: Departamento de Biología Vegetal. Universidad de Santiago de Compostela. C.U. de A Coruña. 